Fikrah: Jurnal Ilmu Aqidah dan Studi Keagamaan

issn 2354-6174 eissn 2476-9649

Tersedia online di: journal.iainkudus.ac.id/index.php/fikrah

Volume 8 Nomor $12020,(1-24)$

DOI: 10.21043/fikrah.v8i1.7216

\title{
Interaksionisme Simbolik Ritual Meron di Indonesia dan Relevansinya dalam al Quran
}

\author{
Ahmad Atabik \\ Institut Agama Islam Negeri Kudus, Kudus, Indonesia \\ atabik78@gmail.com
}

\begin{abstract}
Abstrak
Tulisan ini mengkaji tentang tradisi budaya meron di Pati Indonesia, yaitu sebuah tradisi sebagai penghormatan kepada nabi dengan cara membawa tumpeng yang dibuat dari rengginang besar. Metode yang digunakan adalah penelitian kualitatif dengan pendekatan etnografi yang bertujuan untuk mengetahui makna dari setiap simbol meron. Teori yang digunakan adalah interaksionisme simbolik Herbert Blumer yang menjelaskan tiga asumsi atas simbol, yaitu makna sebagai basis perbuatan manusia, makna yang diciptakan dari interaksi sosial dan makna yang dimodifikasi melalui interpretasi pembaca. Hasil dari tulisan ini adalah bahwa tradisi meron mempunyai relevansi dengan ajaran Islam sebagai bentuk dakwah. Rengginang sebagai simbol dari syukur dan kebersamaan, masjid sebagai simbol religius dan susunan rengginang adalah simbol tingkatan iman, Islam dan ihsan. Relevansi meron terhadap ayatayat al-Quran, sebagaimana dijelaskan dalam QS. al-Baqarah: 260. Rengginang yang terbuat dari nasi diisyaratkan dalam QS. al-Baqarah: 261, dan QS. Al-Fath: 29. Sedangkan simbol masjid dikuatkan dalam QS. At-Taubah: 18-19.
\end{abstract}

Kata kunci: interaksionisme simbolik, meron, al-Quran, tradisi 


\begin{abstract}
This paper examines the cultural traditions of meron in Pati Indonesia. A tradition that is interpreted with respect to the prophet by bringing a cone made from large rengginang. The method used is qualitative research with an ethnographic approach that aims to find out the meaning of each meron symbol. The theory used is Herbert Blumer's symbolic interactionism that narrates three assumptions of symbols, namely meaning as the basis of human action, meaning created from social interaction and meaning modified through reader interpretation. The results of this paper are that the meron tradition has relevance to the teachings of Islam as a form of $d a^{\prime} w a h$. Rengginang as a symbol of gratitude and togetherness, a mosque as a religious symbol and the arrangement of rengginang is a symbol of the levels of Iman, Islam and Ihsan. The relevance of meron to the verses of the Quran, as in the study of QS. alBaqarah: 260. Rengginang made from rice is hinted at in QS. al-Baqarah: 261 and QS. Al-Fath: 29. While the mosque symbol is strengthened in the QS. At-Taubah: 18-19.
\end{abstract}

Keywords: al-Quran, interaction, tradition, symbolic meron,

\title{
PENDAHULUAN
}

Meron adalah kegiatan mengiring nasi tumpeng dibuat dari rengginang besar di daerah Sukolilo, Jawa Tengah. Tepatnya di Bulan Rabiul Awal atau yang lebih terkenal dengan istilah Bulan Mulud sebagai bentuk penghormatan kepada Baginda Nabi Muhamad Saw (Yudiono K. S, 2005, p. 38), yang diikuti oleh banyak warga dari berbagai kalangan, baik masyarakat pedesaan maupun perkotaan berkumpul di tempat pelaksanaan acara meron (Suwito, 2017, p. 3).

Sebagai gerakan sosial (social movement), meron memiliki sejarah tersendiri. Bermula dari pasukan Kerajaan Mataram yang mampu mengalahkan Adipati Pati. Beberapa pasukan Mataram yang ditugaskan di Kademangan Sukolilo, Pati memilih untuk tidak pulang ke Mataram. Mereka meminta izin pada pihak kerajaan Mataram agar diperbolehkan menetap di sana dengan alasan supaya bisa mengendalikan keadaan dari jenis dan bentuk pembangkangan (Marsono, Waridi Hendrosaputro, 1999, p. 202).

Para prajurit juga meminta izin pihak kerajaan agar diperbolehkan melaksanakan kegiatan semacam sekaten di tanggal dua belas Mulud demi mengikuti tradisi serupa di Mataram dan akhirnya diberikan izin yang kemudian diberi nama meron. Kata meron itu sendiri diambil dari dua kata dasar, yaitu ' $m e$ ' yang merupakan potongan kata dari 'rame' (ramai) dan 'ron' yang merupakan kata dari 'tiron-tiron' (meniru-niru) yang sudah ada (Rahmawati, 2019, p. 2). 
Meron merupakan gerakan sosial yang secara mendasar akan berhenti manakala tujuannya sudah tercapai (Wirawan, 2012, p. 109). Misalnya, para mahasiswa melakukan demonstrasi besar-besaran di tahun 1999 ke era reformasi (Muhammad Umar Syadat Hasibuan, 2008, p. 78), revolusi Iran (Pusat Data dan Analisa TEMPO, 2019, p. 8). Namun, hal ini tidak berlaku dalam kegiatan meron (Pramudyani, 2011, p. 2). Kajian tentang meron sesungguhnya sudah banyak dilakukan, misalnya riset Rini Andriani Setianingrum yang membahas tentang "Leksikon dalam Tradisi Meron di Pati", riset ini tidak menyentuh sama sekali relevansi kegiatan meron dengan ayat-ayat al-Quran (Setianingrum, n.d., p. 2). Riset Dwi Tyas Rahmawati, Triyanto dan Purwanto tentang meron sebagai karya seni rupa dalam kajian nilai estetik dan fungsinya pada tradisi perayaan maulid nabi di Desa Sukolilo Pati yang tidak melihat reaksi simboliknya, namun lebih pada sisi relevansinya dengan ayat-ayat al-Quran (Rahmawati, 2019, p. 5).

Riset Niken Henta Pramudyani, tentang upacara tradisi meron dan relevansinya dengan kehidupan masyarakat di Pati, tidak mengaitkannya dengan ayat-ayat al-Quran yang menjadi obyek kajian penulis (Pramudyani, 2011, p. 3). Riset Asri Rahmaningrum Tradisi lebih melihat meron di Desa Sukolilo Pati, lebih pada perspektif dakwah Islam dalam ritual meron (Asri Rahmaningrum, 2015, p. 13). Sedangkan tulisan ini ingin memberikan kontribusi dalam khazanah keilmuan al-Quran dalam menanggapi realitas budaya meron dan tradisi lokal Indonesia, dengan melihat relevansinya pada al-Quran.

\section{Interaksionisme Simbolik}

Interaksi adalah proses saling mempengaruhi, baik di dalam bentuk kegiatan. Simbolik adalah pelambangan yang menunjukkan makna sesuatu. Interaksionisme simbolik adalah proses pembentukan makna antara individu dengan individu, individu dengan kelompok atau pun dengan masyarakat. Dari situ akan muncul hubungan antara interaksi dan simbol (M. Dahlan Y. AlBarry dan L. Lya Sofyan Yacub, 2003, p. 323).

Simbol ada dua jenis. Verbal dan non verbal. Komunikasi verbal adalah komunikasi langsung yang lebih mudah disampaikan. Baik berupa omongan, tulisan atau pun tindakan. Semisal orang yang sedang dipanggil temannya tapi dia menunjukkan jam tangannya. Ini adalah tindakan yang menjadi simbol dengan makna ia sedang terburu-buru dan belum bisa ikut gabung untuk berkumpul (Richard West dan Lynn H Turner, 2001, p. 320). 
Sedangkan simbol non verbal adalah simbol yang tidak langsung. Ia perlu pemahaman dan analisis khusus untuk mengetahuinya (Rachmat Kriyantono, 2017, p. 220). Selain itu, dibutuhkan menganalisis makna simbolsimbol (Richard West dan Lynn H Turner, 2001, p. 320). Interaksionisme simbolik merupakan teori yang memiliki asumsi bahwa manusia bisa membentuk makna tertentu dari proses komunikasi di antara mereka (Richard West dan Lynn H Turner, 2001, p. 97). Menurut Herbert Blumer, ada tiga asumsi dari teori interaksionisme simbolik. Pertama, manusia itu bertindak berdasarkan makna yang diberikan orang lain kepadanya. Kedua, makna itu diciptakan dalam interaksi antar manusia. Ketiga, makna itu bisa dimodifikasi melalu interpretasi pembacanya (Yudhistira Ghalia Indonesia, 1972, p. 16).

Interaksi simbolik bermula dari teori interaksionisme simbolik George Herbert Mead yang kemudian disempurnakan oleh Herbert Blumer. Kinerja teori ini adalah melihat adanya makna dari interaksi sosial yang ada. Semisal kesepakatan bahasa tertentu dengan makna khusus di komunitas tertentu yang tidak dimiliki oleh kelompok sosial lain. Teori ini juga melihat konsep diri atau motif berinteraksi yang dilakukan oleh kelompok tertentu (I.B.Wirawan, 2012, pp. 112-117).

Tiga hal yang menurut Blumer menjadi dasar penting dari teori ini yaitu: meaning, language, dan thought (Michael Farrell, 2012, p. 147). Makna (meaning) itu bisa wujud dari interaksi sosial bersama. Makna itu juga dapat dimodifikasi dengan adanya interpretasi bahasa tertentu. Maka, makna bisa mengalami perluasan atau bahkan penyempitan setelah adanya interpretasi. Bahasa (language) dimaksudkan sebagai media untuk pengungkapan makna yang dikehendaki bersama oleh komunitas. Sehingga penyamaan arti dan maksud dari bahasa itu adalah syarat mutlak untuk mempertegas teori interaksionisme simbolik. Artinya, satu bahasa yang sama pelafalannya dan memiliki makna yang berbeda oleh daerah yang beda itu akan menyebabkan kesulitan mencari benang merah interaksi simboliknya.

Pikiran (thought) adalah syarat mutlak untuk bisa memberikan interpretasi dari simbol tertentu. Di mana bahasalah yang bisa menjadi media untuk menuangkan gagasan dan pikiran. Tiga kata kunci dalam teori ini adalah mind (pikiran), self (konsep diri) dan society (nilai-nilai sosialnya). Menurut Blumer, Mauss, dan Tilly bahwa gerakan sosial itu tidak bersifat terus-menerus karena memiliki siklus hidup kurang-lebih prosesnya adalah diciptakan sebagai awal permulaannya, tumbuh berkembang menjadi sebuah 
gerakan bersama, pencapaian sasaran akhir atau kegagalannya sebagai hasil dari gerakan sosial tersebut, terkooptasi dan kehilangan semangat hingga meredup dan akhirnya hilang begitu saja.

Teori ini mengindikasikan bahwa gerakan sosial itu ada masanya untuk menjadi usang dan tidak terpakai kembali. Hal ini terjadi sebagaimana yang disampaikan pula oleh Ibnu Khaldun bahwa tabiat suatu bangsa atau pun sosial adalah dari embrio, berkembang, membesar dan akan tumbang. Hanya saja Ibnu Khaldun menggariskan bahwa tumbangnya itu manakala bangsa atau negara tertentu telah melakukan kesalahan yang menyebabkan hilangnya kesempurnaan. Hal tersebut dapat dianalisis penyebab asal-muasal kehancuran sebuah negara atau tatanan masyarakat. berikut:

Blumer, Mauss, dan Tilly menggambarkan pergerakan sebagaimana Gambar I

Proses Pergerakan Sosial

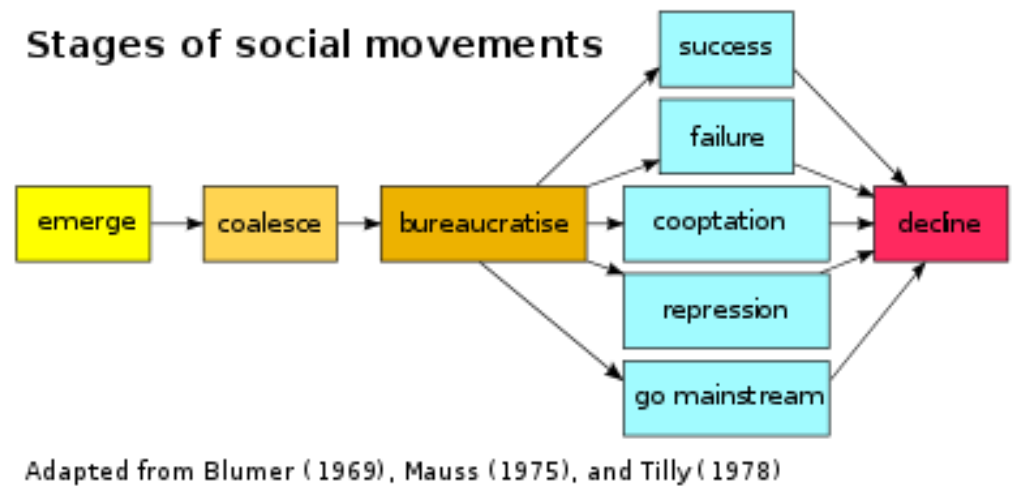

Jika melihat gambar di atas, proses dari gerakan sosial adalah emerge (timbul, muncul) terlebih dahulu, yaitu dari embrio kecil berupa kesamaan rasa beberapa orang akan ketidak-sesuaian realitas dengan idealisme. Misalnya adalah penindasan, ketimpangan sosial, diskriminatif, perilaku koruptif dari pemimpin atau pun keputusan peraturan yang tidak pro rakyat serta motif-motif lainnya.

Kemudian gerakan berikutnya adalah coalesce (bersatu dan bergabung), yaitu gerakan-gerakan kecil itu membentuk persatuan bersama di bawah visi dan misi yang sama pula. Lalu menjadi bureauscratise (birokrasi), yaitu 
organisasi di bawah kepemimpinan tertentu. Di sinilah pergerakan masal itu terjadi dan mereka akan bersama-sama melakukan gerakan yang butuh untuk diperjuangkan.

Nasib manusia ataupun kelompok bisa succes (berhasil), atau failure (gagal tidak tercapai tujuan), cooptation (usaha kerjasama untuk melakukan sesuatu), repression (penindasan) karena mereka kalah dalam melakukan pergerakan sosial atau go mainstream (menjadi hal biasa). Perlu dicatat bahwa ujung dari semua pergerakan sosial dengan beberapa kemungkinan, hasilnya akan bermuara menuju decline, di mana menurun dan mundur-lemahnya gerakan tersebut hingga tidak ada lagi pergerakan-pergerakan lain. Dengan demikian, bahwa pergerakan sosial dalam bentuk apapun akan mengalami kemunduran dan kurang-minatnya para pegiat sosial. Hal ini dapat saja terealisasi karena tabiat pergerakan adalah terwujudnya kebersamaan demi menghasilkan sesuatu yang telah disepakati.

\section{Metode}

Tulisan ini merupakan penelitian kualitatif field research (TO Ihrami, 1999, p. 50), dengan metode deskriptif-analisis (Junaiyah H.M., E. Zaenal Arifin, 2011, p. 113), yang menggambarkan bagaimana kegiatan meron itu dilakukan di daerah Sukolilo Pati. Analisis dimaksudkan untuk mengungkapkan nilai simbol apa yang diharapkan oleh para pelaku hingga eksistensi kegiatan itu masih berlanjut sampai saat ini.

Pengumpulan data melalui observasi, wawancara beberapa pihak yang terkait serta melihat hasil penelitian-penelitian sebelumnya untuk mendapatkan data-data tentang meron. Dengan demikian, diusahakan mendapatkan data utuh dan lengkap sehingga dapat di analisis dengan teori interaksionisme simbolik. Adapun pendekatan yang penulis gunakan pendekatan etnografi_(Suwardi Endraswara, 2006, p. 207), karena kegiatan Meron yang dilakukan oleh masyarakat Sukolilo Pati berbentuk pola dan senantiasa dijalankan oleh masyarakat (Bayu Indra Pratama, 2017, p. 100).

\section{Tradisi Meron di Masyarakat Pati}

Tradisi meron yang dilaksanakan masyarakat Pati, tepatnya di Sukolilo dilaksanakan sejak kerajaan Mataram hingga saat ini. Perhelatan meron melalui tumpeng besar yang terbuat dari berbagai macam rengginang, besar- 
kecil, dengan model yang beragam dihadirkan bersama. Acara dilakukan setiap tahun pada hari yang bertepatan lahirnya Baginda Nabi Saw, dikenal dengan mulud, pada tanggal 12 Rabiul Awal (Yudiono K. S, 2005, p. 38).

Malam harinya, para warga mengadakan acara sedekah khusus yang diisi dengan tirakatan para sesepuh supaya acara pagi harinya bisa berjalan dengan lancar dan memberikan dampak positif. Sekitar jam 06.00 WIB masing-masing warga mengeluarkan meron yang sudah dibuat dan diletakkan di emper rumah. Setelah Dzuhur, meron diarak bersama sepanjang jalan raya sampai menuju Masjid Besar (Jami') dengan jarak sekitar satu kilometer. Biasanya berangkat dari yayasan Sultan Agung menujus ke Masjid (Asri Rahmaningrum, 2015, p. 20).

Perangkat desa bersama penghulu KUA juga ikut hadir meramaikannya. Penghulu yang memimpin upacara meminta keberkahan bersama, kedamaian dan kerukunan warga, kesejahteraan kehidupan rakyat dan amanatnya para pimpinan dan aparat. Setelah upacara doa, meron disuguhkan dan dibagikan kepada warga dan siapa pun yang hadir di acara tersebut (Marsono, Waridi Hendrosaputro, 1999, p. 202).

Ada pergeseran cara dan materi yang digunakan dalam proses upacara meron. Beberapa informasi memberikan gambaran bahwa sebelum tahun 1971 acara meron dilaksanakan sesuai hitungan Aboge (hitungan Jawa, Rebo Wage). Di malam harinya tidak diisi dengan salawat atau pun bacaan al-Quran, namun diisi dengan nonton wayang kulit bersama. Seminggu setelah acara, ada yang membagikan makanan pasar cucur, ampyang dan once (Pramudyani, 2011, p. 30).

Setidaknya ada tiga bagian dalam gunungan makanan yang diarak. Pertama, ayam jago atau ingkung dan masjid sebagai simbol keprajuritan yang gagah nan pemberani yang salih dan religius. Kedua, rengginang atau kerupuk ampyang yang ditaruh di sisi kanan-kirinya. Hal ini menggambarkan solidaritas dan tekad kebersamaan yang tidak mau dipisahkan hanya masalah kepentingan duniawi sesaat. Ketiga, penopang atau ancak yang terdiri tiga bagian: atas, tengah, dan bawah. Hal ini merupakan simbol tentang iman, Islam dan ihsan yang diajarkan Nabi Muhammad Saw (Suwito, 2017, p. 3). Sebagaimana gambar meron yang diarak: 


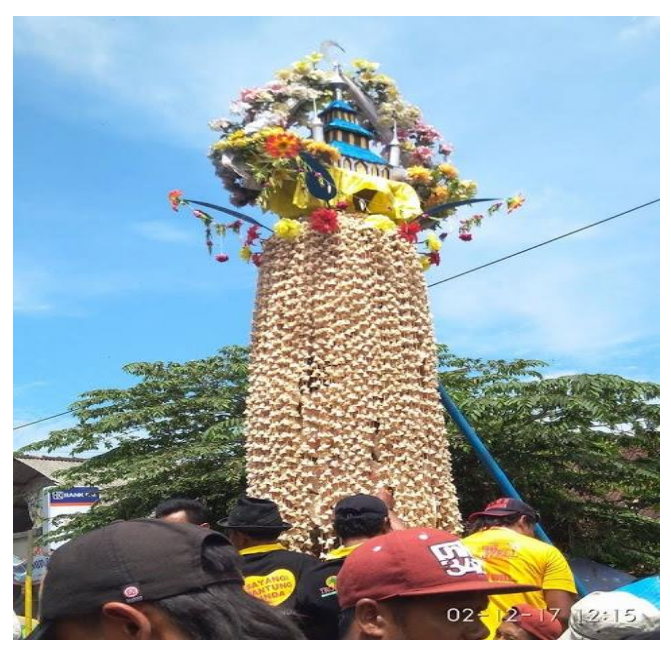

Beberapa sumber menyebut bahwa meron adalah manifestasi syukur mereka atas anugerah Tuhan YME berupa nikmat, ketentraman dan terlebihnya adalah atas kelahiran Nabi Agung Muhammad Saw. Meron yang diarak berjumlah empat belas yang melambangkan komitmen tiga belas desa beserta perangkat dan rakyatnya untuk berhidup damai, rukun dan beragama. Menurut Kepala Desa Sukolilo, kegiatan meron ini hampir sama dengan sekaten di Surakarta. Bahkan menurutnya, Sukolilo itu masih memiliki garis keturunan dengan Surakarta. Sehingga jika di sana ada sekaten, maka di Sukolilo ada meron. Dijelaskan juga bahwa masyarakat di Sukolilo hanya melanjutkan tradisi yang sudah ada sejak dulu.

Penulis mendapatkan informasi tentang banyaknya pengunjung meron ini dan membaur menjadi satu. Sehari bisa mencapai ribuan orang. Selain itu, upacara meron dihadiri oleh para pembesar, pejabat dan rakyat kecil. Meron tidak mengenal suku, kasta, bahasa, daerah, dan apa pun penyekat persatuan. Maka, tidak berlebihan jika para tetua dan sesepuh mengharapkan meron sebagai salah satu media pemersatu penduduk Sukolilo dan sekitarnya. Hal ini tidak terlepas selama ini konflik yang terjadi di masyarakat Sukolilo masih sering terjadi, yang bermula dari urusan pribadi menjadi urusan kelompok dan apada akhirnya menimbulkan kekerasan.

Motivasi para penggunjung meron beragam, diantaranya: untuk mendapatkan berkat. ingin memiliki pekerjaan myang apan, usaha yang semakin maju, keluargayang utuh kembali (setelah terjadi perceraian), mendapatkan jodoh setelah pulang dari menghadiri meronI. Sebagaimana 
yang dialamai salah satu informan menyampaikan bahwa di tahun sebelumnya, anak putri mereka diminta untuk mengikuti kegiatan meron dan mengambil rengginang yang dibagikan secara gratis dengan tujuan supaya mendapatkan jodoh. Saat anak gadisnya mengikuti meron dan sepulang dari acara tersebut, bertemu dengan pemuda yang akhirnya menjadi jodohnya, hal ini disampaikan orang tuanya, tidak terlepas dari keberkahan acara mengikuti acara meron.

\section{Interaksionisme Simbolik Kegiatan Meron}

Ada beberapa simbol dalam kegiatan meron di Sukolilo, diantaranya bertingkatnya ancak, lambang masjid dan ayam jago serta kerupuk ampyang atau rengginang (Rahmawati, 2019, p. 10). Penulis membaca dan menginterpretasikan akan lambang-lambang tersebut dengan mencari korelasinya pada kondisi dan situasi awal terbentuknya kegiatan meron. Ancak sesungguhnya memiliki makna awal sebagai talam atau penampan yang digunakan untuk menaruh sesajen yang diberikan kepada arwah-arwah leluhur atau lelembut (bangsa gaib) agar memberkati perbuatan manusia, menolong hajat mereka atau menyatakan rasa syukur atas karunia yang dipercayai ada kaitannya dengan bangsa (Wahyana Giri M. C., 2010, p. 43). Simbolik sesajen disebabkan keyakinan animisme-dinamisme masih sangat kuat di masyarakat Jawa. Mereka menyembah arwah dan benda-benda yang dianggap sakral, seperti batu, berhala, hewan dan benda-benda yang diagungkan saat itu (Proyek Pusat Pengembangan Kebudayaan Kalimantan Timur, 1979, hlm. 279).

Sesajen biasanya terdiri dari bunga tujuh rupa, air, beras atau nasi, ingkung ayam dan jajan pasar (Wahyana Giri M. C., 2010, hlm. 25). Semua ini sebagai lambang dan simbol yang memiliki makna tersendiri. Bunga adalah simbol keindahan, estetika dan kesempurnaan sebagai manusia yang patut bersyukur kepada Sang Pencipta. Nasi tumpeng adalah simbol dari tumungkulo mempeng (bekerja dengan keras dan cerdas). Ingkung ayam adalah lambang cinta kasih dan pengorbanan, sedangkan jajan pasar adalah lambang kebersamaan sebagai umat manusia yang dituntut membangun harmoni satu dengan yang lainnya. Tentunya kegiatan tersebut dikemas dengan berbagai nilai-nilai keislaman, sehingga tidak lagi murni animisme-dinamisme.

Ancak yang semestinya digunakan sebagai sesajen dimodifikasi sedemikian rupa menjadi penopang masjid. Sumber dari informan bahwa hal ini merupakan simbol tinggi yang menjadi pelajaran masyarakat desa, bahwa 
budaya apa pun yang ada sudah semestinya dapat diikutkan masjid yang merupakan lambang ketauhidan. Artinya, kebiasaan dan tradisi buruk yang dilakukan orang Jawa ketika itu tidak harus dihilangkan sama sekali, tetapi diarahkan untuk menuju nilai-nilai Islam. Sebagaimana tradisi tayub, gending, gong dan wayang kulit yang dijadikan alat Sunan Kalijaga untuk mengislamkan tanah Jawa. Ancak yang menjadi penyangga masjid dapat diartikan akan pentingnya kerukunan bersama di dalam beragama. Tidak boleh ada egois dan ingin menang sendiri dalam menafsirkan keagamaan. Bersama dalam kesepakatan dan toleransi dalam perbedaan adalah makna yang ada di dalamnya.

Rengginang atau ampyang yang terbuat dari bahan dasar nasi itu sesungguhnya memiliki simbol multi-interpretatif. Sebagaimana nasi menjadi lambang akan kebutuhan penduduk pada nasi yang menjadi makanan pokok, menjadi simbol syukur tingkat tinggi karena diberikan kekayaan dan kecukupan pangan oleh Tuhan YME (Ekawati Marhaenny Dukut, 2020, p. 251). Rengginang yang dikumpulkan menjadi satu-kesatuan simbol kerukunan dan kebersamaan masyarakat. Semangat berbagi dan menghilangkan sikap egois merupakan makna simbolik. Makanan pokok yang dibutuhkan masyarakat harus mampu menjadi media untuk bersama, saling memberi dan bahkan memperhatikan masyarakat sekitar yang kurang mampu.

Tingkatan ancak juga memberikan pengertian tiga istilah utama dalam Islam, yaitu iman, Islam dan ihsan. Semuanya adalah ajaran penting dalam berislam dan harus dipatuhi semua pemeluknya. Tingkatan ini juga memberikan makna bahwa beragama itu perlu proses, tidak dengan tiba-tiba seseorang mengaku beragama Islam dan mencapai tingkat hakikat dengan sufismenya atau aliran kebatinan dan lainnya tanpa mengetahui terlebih dahulu bagaimana dan apa sesungguhnya ajaran-ajaran mendasar dalam Islam.

Hal tersebut menjadi sangat wajar, mengingat masyarakat Sukolilo dan sekitarnya adalah wilayah abang (penduduk yang mengikuti ajaran kepercayaan). Mereka banyak yang mengenal Islam dari kulitnya saja dan kurang memahami apa dan bagaimana sesungguhnya makna dari ajaran Islam (Abd. Moqsith Ghazali, 2009, p. 405). Misalnya masyarakat Suku Samin yang banyak tinggal di Sukolilo. Mereka berperilaku baik dengan tidak mengganggu orang lain dan banyak mengajarkan kemandirian, tidak menyakiti orang lain, baik dengan kedua orang tua dan ajaran mulia lainnya. 
Namun, sikap eksklusif masih banyak yang mereka lakukan dengan enggan untuk taat aturan pemerintah dan tidak ingin terikat dengan agama tertentu.

Maka, wajar jika perayaan meron dengan segala simboliknya mengajarkan betapa perlunya proses dalam beragama. Menjadi lebih baik, tenang, khusyuk dan merasa menjadi hamba Tuhan di mana pun dan kapan pun saja. Beragama hanya mengandalkan hakikat dan inti dalam ajaran saja tidak cukup. Namun, harus melewati ruang syariat-tarekat juga. Hal demikian untuk menghindari klaim sepihak menjadi penganut Islam yang paling benar dan lainnya dianggap salah.

Sebaliknya, beragama Islam tidak diperbolehkan hanya berhenti di dalam syariat semata, misalnya hanya shalat, puasa, haji, bersedekah, dan zakat, yang sebatas menjadi rutinitas dan amalan luar tanpa penghayatan. Jika demikian, amal ibadah tersebut akan kering yang tidak dapat dinikmati oleh pelakunya. Padahal inti beragama tidak hanya menjadi orang baik dalam pelaksanaan rutinitas ritual semata, tetapi memiliki rasa penuh menghamba kepada Tuhan. Hal inilah yang sesungguhnya nilai simbolik yang ingin dituangkan dalam proses kegiatan meron tersebut.

\section{Relevansi Kegiatan Meron dengan Ayat-Ayat al-Quran}

Kajian relevansi ini bertujuan agar para pemerhati budaya dan tradisi tertentu memiliki pemahaman bahwa nilai-nilai Islam dalam warisan leluhur itu sangat kuat (Effendi, 2017, p. 3). Sehingga kajian semacam ini diharapkan tidak memberikan ruang justifikasi oleh kelompok tertentu kepada tradisitradisi leluhur. Pertama, masjid dan ayam ingkung yang ditaruh di bagian paling atas, merupakan simbol keberagamaan tinggi yang diinginkan oleh masyarakat Sukolilo. Masjid adalah lambang ketaatan kepada Allah SWT (Hasyim, 2011, p. 2). Sebab, masjid adalah tempat beribadah, berzikir, shalat dan membaca al-Quran. Maka, nilai-nilai ibadah yang kaitannya dengan hablu minallah (hubungan vertikal) diharapkan mampu dibawa ke tengahtengah masyarakat sebagai bentuk hablu minannas (hubungan horizontal) (Chakim, 2016, p. 43).

Relevansi simbol ini dengan QS. at-Taubah ayat 18, bahwa orangorang yang memakmurkan masjid adalah mereka yang beriman kepada Allah SWT, hari kiamat, mendirikan shalat dan zakat. Seakan simbol itu mengindikasikan kuat bahwa masyarakat Sukolilo berharap untuk bisa memakmurkan masjid dan menjadikannya sebagai kiblat semua kegiatan 
masyarakat (Fakhruddin ar-Razi, 2017, p. 8). Miniatur masjid yang dibawa dan diarak adalah lambang bahwa mereka berharap supaya nuansa di masjid itu tetap selalu ada dan dirasakan oleh masyarakat (Utaberta et al., 2012, p. 10). Masyarakat merasa dipantau Allah SWT, maka perlu adab-etika dalam berbuat, berbicara dan bertindak. Selain itu membiasakan sikap tenang, tidak mudah terpancing amarah hanya karena masalah-masalah yang semestinya dapat diselesaikan secara baik-baik di antara mereka. Begitu juga hal-hal positif lainnya dapat benar-benar direnungi dan dipraktekkan di kehidupan nyata (Abror, 2016, p. 64).

Arakan miniatur masjid adalah ajaran simbolik yang sesuai dengan satu hadis Nabi Saw, menjelaskan bahwa di antara tanda-tanda orang yang akan diberi naungan Allah SWT di hari tiada naungan melainkan dari-Nya adalah mereka yang hatinya selalu digantungkan ke masjid (dalam kondisi dan situasi apa pun) (Muhamad bin Ismail al-Bukhari, 1987, p. 133). Perayaan meron juga memberikan lambang ingkung ayam jago yang ditaruh di dekat masjid. Mengapa ayam, bukan burung atau unggas lainnya? Ada banyak penafsiran dalam hal ini (Sulistiyaningsih, 2017, p. 8). Penulis mengkaitkan dengan simbolik ayam dalam sejarah, misalnya dalam kisah Nabi Ibrahim as yang diperintahkan Allah untuk menyembelih empat burung. Para ulama banyak menafsirkan sebagai lambang yang memiliki makna tersendiri.

Penulis mendapatkan beberapa penafsiran yang hampir berdekatan (Mukhamad Ali as-Shabuni, 2004, p. 70) terhadap QS. Al-Baqarah ayat 260, bahwa suatu ketika Ibrahim meminta kepada Allah SWT, agar diperlihatkan bagaimana Dia menghidupkan orang mati? Ibrahim ditanya apakah ia tidak percaya? Lalu ia menjawab bahwa ia sangat percaya namun ia ingin hatinya puas dan lega. Maka, ia disuruh untuk mengambil empat burung yang dipotong-potong bagian tubuhnya dan ditaruh di beberapa pegunungan dan diminta untuk dipanggil semua, maka burung itu akan hidup kembali terbang menghampirinya. Ketika itu ia benar-benar percaya dengan kuasa-Nya.

Al-Khalwati menjelaskan bahwa empat burung yang dimaksud di atasa adalah ayam jago, burung gagak, burung cenderawasih dan burung bangkai. Ayam jago menjadi pelambang dari syahwat bersetubuh manusia. Burung cenderawasih menjadi lambang sifat pamer umat manusia. Burung gagak menjadi lambang sikap rakus nan kejam-bengisnya manusia dan burung bangkai adalah lambang kebodohan dalam menanggapi duniawi, semua diperintahkan untuk membunuh agar manusia dapat kembali suci menuju keharibaanNya (Ahnaf bin Muhamad al-Khalwati, 2014, p. 200). 
Penulis memahami bahwa ayam jago yang merupakan lambang dari puncak nikmat tertinggi manusia (yaitu bersetubuh) harus takluk dan tunduk dengan masjid. Artinya, manusia siapa pun harus mampu mengendalikan syahwat terkuatnya. logikanya, jika syahwat tertinggi saja harus ditundukkan di depan masjid, maka apalagi dengan syahwat-syahwat lainnya. Kedua, simbol ancak, ancak yang terbuat dari rengginang memberikan makna syukur yang luar biasa dari umat manusia kepada Tuhannya yang telah menganugerahkan makanan pokok (nasi yang berbentuk rengginang) di daerah mereka. Tepatnya adalah sedekah dari mereka yang ditujukan kepada Sang Maha Kuasa. Kenapa nasi? Filosofisnya sangat mendalam sekali (Abdurrohman, 2016, p. 9) dan dapat dikaitkan pula dengan QS. al-Baqarah ayat 261.

Ayat di atas memberikan penjelasan bahwa perumpamaan mereka yang bersedekah itu seperti habbah. Beberapa sumber menyebutkan bahwa kata habbah itu dibahasakan oleh orang Jawa dengan nama gabah, yaitu pepadian yang belum diproses menjadi nasi dan masih asli dan berada di gagang padi atau jeraminya sebelum dipanen. Allah SWT mengibaratkan sedekah dengan biji padi (Wahbah az-Zuhaili, 1997, p. 41), sehingga orang Jawa menyimbolkan sedekah dengan nasi.

Apa sifat gabah yang disebutkan al-Quran itu? Gabah memiliki keunikan yang tidak dimiliki oleh tetumbuhan yang lain. Bahkan ada sumber yang menyebutkan bahwa ayat di atas sesungguhnya adalah ayat bernunsa Jawa. Kenapa? Karena habbah yang dikaitkan dengan pepadian itu tidak ada di masyarakat Arab kuno ketika al-Quran turun. Sebab, kebiasaan masyarakat Arab adalah bercocok tanam gandum, kurma atau pun anggur dan zaitun (Hitti, 2006, pp. 22-26). Keunikan gabah dimulai dari proses penanamannya, induk biji yang digunakan kira-kira hanya seperempat dari hasil panennya. Lalu yang lain dari mana? Ia mengembang diri dengan mengeluarkan jerami (sunbulah) atau tangkai yang setiap tangkainya berbuah biji-biji lain yang mirip dengan induk bijinya tadi. Berapa jumlahnya? Al-Quran menginformasikan sebanyak seratus biji di setiap tangkainya. Ada berapa tangkai dalam satu induk biji? Al-Quran juga mengabarkan ada tujuh tangkai sehingga dalam satu induk biji itu bisa mengeluarkan tujuh ratus biji (Fakhruddin ar-Razi, 2017, pp. 499-500).

Gabah juga punya keunikan lain. Cara tumbuhnya yang berbeda dengan yang lain. Ini digambarkan oleh QS. Al-Fath ayat 29 bahwa perumpamaan umat Islam seperti benih yang mengeluarkan tunasnya. Kemudian tunas itu 
membesar, kuat dan tegak lurus di atas batangnya (Fakhruddin ar-Razi, 2017, pp. 87-89). Sebagian sumber menyebut bahwa ayat ini menjadi lambang akan pentingnya peran orang tua di dalam keluarganya. Umat Islam tidak diperbolehkan hanya berfikir tentang dirinya sendiri. Namun, keluarga dan anak-anaknya juga tidak boleh ditinggalkan dalam keadaan lemah iman, Islam, dunia dan hal-hal positif lainnya. Semangat tersebut tertuang pula dalam QS. an-Nisa ayat 9 dan QS. at-Tahrim ayat 6.

Itulah di antara alasan menggunakan rengginang yang terbuat dari nasi dalam perayaan meron. Diharapkan para generasi berikutnya memahami arti pentingnya kehidupan ini, apa saja yang perlu dilakukan dan cara syukur yang tepat guna di dalamnya. Nilai-nilai semacam ini yang menurut para sesepuh di Sukolilo dapat dipahami, diresapi dan diamalkan oleh generasi sekarang, bukan hanya sekedar seremonial upacara budaya.

Ketiga, bertingkatnya ancak yang ada. Tepatnya adalah dalam tiga tingkatan, mempunyai relevansi dengan ayat-ayat al-Quran dan hadis Nabi Saw yang mengajarkan tiga istilah penting dalam beragama. Kisah Jibril as yang datang pada Nabi Saw dan bertanya tentang iman, Islam dan ihsan. Kemudian dijawab Nabi Saw bahwa iman adalah meyakini adanya Allah SWT, malaikat, nabi-rasul, kitab-kitab Allah SWT, hari kiamat dan takdir Allah SWT. Islam dijelaskan Nabi Saw sebagai perbuatan umat Islam yang menjalankan shalat, membayar zakat, membaca syahadat, melaksanakan puasa Ramadhan dan berhaji ke Baitullah. Sedangkan ihsan digambarkan Nabi Saw sebagai beribadah kepada Tuhan seakan-akan melihatNya atau setidaknya meyakini betul bahwa Tuhan Maha Penglihat (Muhamad bin Ismail al-Bukhari, 1987, p. 19).

Ayat-ayat al-Quran yang menjelaskan hal ini juga banyak sekali. Semisal saja QS. an-Nisa: 136, al-A'raf: 158, an-Nur: 62, al-Fath: 9, 13, alHujurat: 15, al-Hadid: 7, al-Mujadalah: 4, as-Shaff: 11 dan at-Taghabun: 8. Ayat-ayat tersebut mengajarkan akan pentingnya iman yang dimanifestasikan dengan amal-amal saleh. Begitu pula dengan QS. alBaqarah: 195, 236, Ali Imran: 134 dan QS. al-Maidah: 93 yang mengajarkan akan pentingnya ihsan.

Ada relevansi paling penting dalam kegiatan meron ini dengan ayatayat al-Quran yang berbicara tentang syukur. Sebagaimana yang dijelaskan oleh beberapa sumber, kegiatan meron sesungguhnya adalah bentuk rasa bersyukur masyarakat Sukolilo akan karunia dan nikmat yang diberikan 
Tuhan YME kepada mereka. Terlebih syukur akan kelahiran Baginda Nabi Muhammad Saw yang dimanifestasikan dengan kegiatan meron ini ada relevansinya dengan QS. Yunus: 85. Ayat yang mengajarkan bahwa hanya dengan rahmat, karunia dan anugerahNya manusia itu harus senang dan bergembira. Banyak ulama yang menjelaskan tafsir ayat ini adalah kegembiraan umat Islam atas kelahiran Baginda Agung Muhamad Saw.

Al-Mawardi menjelaskan bahwa Ibnu Abbas dan ad-Dhahhak menafsirkan kata rahmat adalah Islam dan al-Quran. Imam Mujahid yang menafsirkan rahmat itu adalah al-Quran dan Islam. Ulama lain menjelaskan bahwa rahmat itu adalah iman dan makrifat. Ibnu Abbas ra juga menafsirkan bahwa rahmat itu adalah kelahiran Nabi Muhammad Saw yang merupakan golongan suku Quraisy (Ali bin Muhamad al-Mawardi, 2010, p. 440).

Ayat di atas mengindikasikan bahwa kebahagiaan hakikat itu bukan karena kenikmatan jasmani semata. Semisal kaya raya, badan sehat, punya istri, anak dan keluarga yang baik, bisa kecukupan papan, sandang dan pangan yang mewah dan nikmat, tempat tinggal dan sejenisnya. Sebab, nikmat-nikmat ini sangat rentan dan mudah sekali hilangnya. Bahkan kenikmatannya pun masih tercampur dengan kesedihan. Baik ketika mau mendapatkan yang penuh perjuangan, saat merasakan kenikmatannya yang penuh godaan atau pun setelah kehilangan darinya yang sangat menyakitkan (Jaapar \& Azahari, 2011, p. 3).

Bahagia yang sesungguhnya adalah tentang nikmat immateri, yaitu anugerah Islam dan iman lantaran adanya Nabi Saw, al-Quran dan petunjuk para ulama. Rasa bersyukur itu harus dipupuk dengan hal-hal yang konstan tidak temporal. Sehingga ia pun akan bersifat permanen (Ashari \& Dahriyanto, 2016, p. 9). Bahkan nikmat-nikmat itu semua patut menjadi kebahagiaan bukan karena nikmatnya itu sendiri. Namun karena itu semua adalah anugerah Allah Sang Maha Abadi sehingga syukur pun akan senantiasa dalam puncak keabadian, dan itulah hakikat kebahagiaan (Fakhruddin ar-Razi, 2017, p. 270).

Semangat ini pulalah yang nampaknya menjadi penyebab dan alasan dari masyarakat Sukolilo Pati yang ingin tetap mengabadikan kegiatan meron. Logikanya adalah ketika meron itu adalah manifestasi syukur kepada Tuhan SWT yang telah menganugerahkan keimanan, keislaman, mengikuti Nabi Saw, taat pada sesepuh dan ulama, hidup rukun, tenteram, kecukupan rizki dan nikmat-nikmat lainnya yang bersifat abadi, maka kegiatan meron juga 
tetap dilakukan. Ini adalah salah satu bentuk kearifan lokal daerah Sukolilo (Tiani, 2018, p. 138).

Meron ini berbeda dengan teori gerakan sosial yang disampaikan oleh Blumer (Prasisko, 2016, p. 3). Yaitu jika gerakan sosial sudah mencapai puncaknya maka ia akan mengalami penurunan. Teori ini menjadi tidak terpakai bukan karena tidak tepatnya, namun perbedaan motivasi yang ditimbulkan olehnya. Jika gerakan sosial itu hanya bersifat politik, ekonomi murni atau kepentingan kelompok tertentu saja (Nugraha \& others, 2018, p. 7), maka bisa saja teori itu bisa dilakukan (Martiningsih \& others, 2017, p. 4). Sedangkan, jika gerakan sosial dalam hal ini adalah kegiatan meron itu termotivasi oleh rasa syukur kepada Tuhan YME, maka ia tidak mengenal kata surut dan pelakunya tetap termotivasi untuk melakukannya (Jurdi, 2013, p. 10).

Secara meaning, kegiatan meron ini memberi arti sebagai bentuk syukur atas kelahiran Nabi dan pemberian gemah-ripah (kesejahteraan) Tuhan kepada Masyarakat Sukolilo. Arti ini bisa diinterpretasikan dengan motif para pengunjung dan penduduk setempat yang ikut hadir di sana demi nguri-nguri budoyo (menjaga keutuhan budaya) yang diberikan oleh leluhur mereka (Puddephatt, 2009, p. 90).

Kegiatan meron juga menjadi bahasa budaya setempat yang telah disepakati bersama. Yaitu pesan yang ingin disampaikan penduduk sana berupa keakuran dan keakraban bersama untuk satu tujuan yaitu menghormati insan mulia Nabi Muhamad Saw. Pesan kedamaian adalah tujuan utama dari meron. Inilah yang didengungkan dan diharapkan oleh para aparat, pejabat setempat dan tetua Sukolilo (Darmastuti, 2015, p. 7). Sebab, Sukolilo dan sekitarnya adalah daerah rawan perkelahian, bahkan seringkali ada perang saudara. Maka, meron tetap dijalankan hingga saat ini dengan harapan mampu untuk meredam emosi masing-masing pihak dengan mengingatkan kembali masa lalu mereka dan budaya warisan leluhur (Aksan et al., 2009, p. 903).

Thought yang dimaksud di sini adalah mencari makna simbolik dari tradisi meron dengan segenap lambangnya (Maines, 1989, p. 166). Peneliti mendapatkan bahwa kegiatan meron tidak hanya menjadi kegiatan formalitas semata. Meron memiliki makna simbolik kehidupan dan sosial. Penduduk Sukolilo ingin memperlihatkan kepada dunia bahwa mereka ingin melanjutkan warisan budaya leluhur mereka. Oleh karena itu, meskipun 
tujuan awalnya meron hanya untuk mengikuti kegiatan di Surakarta, namun meron tetap berjalan karena merupakan warisan leluhur. Di samping itu, meron punya beberapa makna simbolik dari piranti dan media yang digunakan.

\section{Simpulan}

Interaksionisme simbolik dalam kegiatan meron tampak dalam makna yang dibuat oleh kelompok sosial di Indonesia. Lambang masjid sebagai religiositas tinggi yang ada relevansinya dengan ayat-ayat al-Quran tentang pemakmuran masjid. Ingkung sebagai simbol dari bukti kesalehan dengan mampu mengendalikan hawa nafsu dan syahwat yang memiliki relevansi dengan QS. al-Baqarah: 260 dalam beberapa penafsiran ulama. Kemudian rengginang yang melambangkan syukur atas karunia besar, mengambil pelajaran dari biji pepadian dan totalitas ketulusan serta kebersamaan. Di mana hal ini memiliki relevansi dengan QS. al-Baqaraah: 261 dan QS. Al-Fath: 29. Sedangkan tingkatan ancak menyimbolkan pentingnya proses dan bertingkat dalam beribadah. Hal ini memiliki relevansi dengan QS. al-Hujurat: 14. Dalam teori Blumer, meron memiliki arti syukur oleh penduduk di Sukolilo. Bahasa persatuan yang ingin disampaikan di dalamnya juga kuat sekali. Sehingga hal ini menjadi ketertarikan penulis untuk melihat aspek makna simbolik meron dan media yang digunakan.

\section{Referensi}

Abd. Moqsith Ghazali. (2009). Merayakan Kebebasan Beragama: Bunga Rampai Menyambut 70 Tahun Djohan Effendi. Penerbit Buku Kompas.

Abdurrohman, M. (2016). Memahami Makna-Makna Simbolik Pada Upacara Adat Sedekah Laut di Desa Tanjungan Kecamatan Kragan Kabupaten Rembang. Jurnal The Messenger, 7(1), 27. https://doi.org/10.26623/themessenger.v7i1.286

Abror, I. (2016). AKTUALISASI NILAI-NILAI BUDAYA MASJID PATHOK NEGORO. ESENSIA: Jurnal Ilmu-Ilmu Ushuluddin, 17(1), 63. https://doi.org/10.14421/esensia.v17i1.1279

Ahnaf bin Muhamad al-Khalwati. (2014). Hasyiyah Ala Tafsir al-Jalalain. Dar 'Alam al-Kutub.

Aksan, N., Kısac, B., Aydın, M., \& Demirbuken, S. (2009). Symbolic interaction theory. Procedia-Social and Behavioral Sciences, 1(1), 902-904.

Ali bin Muhamad al-Mawardi. (2010). An-Nukat wa al-Uyun. Dar al-Kutub al'Ilmiyah. 
Ashari, O. B., \& Dahriyanto, L. F. (2016). Apakah orang miskin tidak bahagia? Studi fenomenologi tentang kebahagiaan di Dusun Deliksari. Intuisi: Jurnal Psikologi Ilmiah, 8(1), 40-46.

Asri Rahmaningrum. (2015). Tradisi Meron Di Desa Sukolilo Kecamatan Sukolilo Kabupaten Pati Dalam Perspektif Dakwah Islam. UIN Walisongo Press.

Bayu Indra Pratama. (2017). Etnografi Dunia Maya Internet. Universitas Brawijaya Press.

Chakim, S. (2016). Dakwah clan Dialektika Budaya Jawa dalam lintasan Sejarah. KOMUNIKA: Jurnal Dakwah dan Komunikasi, 2(1), 42-53. https://doi.org/10.24090/komunika.v2i1.809

Darmastuti, R. (2015). Gerakan sosial tanpa kekerasan (gerakan sosial masyarakat Samin terhadap rencana pembangunan pabrik semen di Sukolilo, Pati). PAX HUMANA, 2(3 Sep), 189-204.

Effendi, K. (2017). LOGO ATAU LAMBANG MERUPAKAN BENTUK NILAI MORAL ISI BIMBINGAN DAN KONSELING. 11.

Ekawati Marhaenny Dukut. (2020). Kebudayaan, Ideologi, Revitalisasi dan Digitalisasi Seni Pertunjukan Jawa dalam Gawai. SCU Knowledge Media.

Fakhruddin ar-Razi. (2017). Mafatih al-Ghaib. Dar 'Alam al-Kutub.

Hasyim, M. (2011). Makna Arsitektur Masjid Pakualaman dalam Tinjauan Kosmologi Jawa. Analisa, 18(2), 211. https://doi.org/10.18784/analisa.v18i2.134

Hitti, P. K. (2006). History of The Arabs. Serambi Ilmu.

I.B.Wirawan. (2012). Teori-Teori Sosial dalam Tiga Paradigma: Fakta Sosial, Definisi Sosial, dan Perilaku Sosial. Kencana.

Jaapar, N. Z. H., \& Azahari, R. (2011). Model keluarga bahagia menurut Islam. Jurnal Fiqh, 8, 25-44.

Junaiyah H.M., E. Zaenal Arifin. (2011). Keutuhan Wacana. Grasindo.

Jurdi, S. (2013). Gerakan Sosial Islam: Kemunculan, Eskalasi, Pembentukan Blok Politik dan Tipologi Artikulasi Gerakan. JPP (Jurnal Politik Profetik), 1(1).

M. Dahlan Y. Al-Barry dan L. Lya Sofyan Yacub. (2003). Kamus Induk Istiliah Ilmiah. Target Press.

Maines, D. R. (1989). Herbert Blumer on the possibility of science in the practice of sociology: Further thoughts. Journal of Contemporary Ethnography, 18(2), 160177.

Marsono, Waridi Hendrosaputro. (1999). Ensiklopedi Kebudayaan Jawa. Yayasan Studi Jawa, Lembaga Studi Jawa.

Martiningsih, D., \& others. (2017). Peran Masyarakat Madani Mewujudkan Clean Government (Pemerintahan Yang Bebas Korupsi Kolusi Dan Nepotisme). PUSAKA, 5(2), 201-218.

Michael Farrell. (2012). New Perspectives in Special Education: Contemporary Philosophical Debates. Routledge. 
Muhamad bin Ismail al-Bukhari. (1987). Al-Jami' ash-Shahih al-Musnad al-Muttasil Ila Rasulillah saw. Dar asy-Syu'ab.

Muhammad Umar Syadat Hasibuan. (2008). Revolusi Politik Kaum Muda. Yayasan Obor Indonesia.

Mukhamad Ali as-Shabuni. (2004). At-Tibyân Fî 'Ulûmi al-Qur'an. DKI.

Nugraha, F., \& others. (2018). Gerakan Ekonomi Keagamaan Dan Politik Identitas Muslim Pedesaan. Jurnal Bimas Islam, 11(4), 693-722.

Pramudyani, F. N. H. (2011). UPACARA TRADISI MERON RELEVANSINYA DENGAN KEHIDUPAN MASYARAKAT DESA SUKOLILO KABUPATEN PATI. 1(2), 8.

Prasisko, Y. G. (2016). Gerakan Sosial Baru Indonesia: Reformasi 1998 dan Proses Demokratisasi Indonesia. Jurnal Pemikiran Sosiologi, 3(2), 9-16.

Proyek Pusat Pengembangan Kebudayaan Kalimantan Timur (Indonesia). (1979). Kumpulan Naskah Kesenian Tradisional Kalimantan Timur. Departemen Pendidikan dan Kebudayaan, Proyek Penerbitan Buku Bacaan dan Sastra Indonesia dan Daerah.

Puddephatt, A. (2009). The search for meaning: Revisiting Herbert Blumers interpretation of GH Mead. The American Sociologist, 40(1-2), 89-105.

Pusat Data dan Analisa TEMPO. (2019). Revolusi Iran-Seri II. Tempo Publishing.

Rachmat Kriyantono. (2017). Teori-Teori Public Relations Perspektif Barat \& Lokal: Aplikasi Penelitian \& Praktik. Kencana.

Rahmawati, D. T. (2019). MERON SEBAGAI KARYA SENI RUPA: KAJIAN NILAI ESTETIK DAN FUNGSINYA DALAM TRADISI PERAYAAN MAULID NABI DI DESA SUKOLILO PATI. 8.

Richard West dan Lynn H Turner. (2001). Pengantar Teori Komunikasi Analisis dan Aplikasi. Penerbit Salemba.

Setianingrum, R. A. (n.d.). LEKSIKON DALAM TRADISI MERON DI SUKOLILO KABUPATEN PATI. 17.

Sulistiyaningsih, C. (2017). MAKNA SIMBOLIK MAKANAN PADA UPACARA TRADISIONAL PAGER BUMI REBO WEKASAN DI DUSUN PULESARI, SLEMAN. Jurnal Student Pendidikan UNY, 2(1), 9.

Suwardi Endraswara. (2006). Metode, Teori, Teknik Penelitian Kebudayaan. Pustaka Widyatama.

Suwito. (2017). Mungkin Segalanya Mungkin: Otobiografi Suwito. YPM Press.

Tiani, R. (2018). Kearifan Lokal Sebagai Bentuk Kontrol Sosial Masyarakat Sukolilo. Nusa: Jurnal Ilmu Bahasa Dan Sastra, 13(1), 137-146.

TO Ihrami. (1999). Pokok-Pokok Antropologi Budaya. Yayasan Obor Indonesia.

Utaberta, N., Sojak, S. D. M., Surat, M., Che-Ani, A. I., \& Tahir, M. M. (2012). Typological Study of Traditional Mosque Ornamentation in Malaysia - Prospect of Traditional Ornament in Urban Mosque. IJCASE, 6(7), 8. 
Wahbah az-Zuhaili. (1997). Tafsir al-Munir. Dar al-Kutub al-'Ilmiyah.

Wahyana Giri M. C. (2010). Sajen dan Ritual Orang Jawa. Penerbit Narasi.

Yudhistira Ghalia Indonesia. (1972). Sosiologi 1. Yudhistira Ghalia Indonesia.

Yudiono K. S. (2005). Cerita Rakyat dari Pati, Jawa Tengah. Grasindo. 